\title{
NMR- AND GCMS -BASED METABOLOMICS APPROACH OF Morinda citrifolia
}
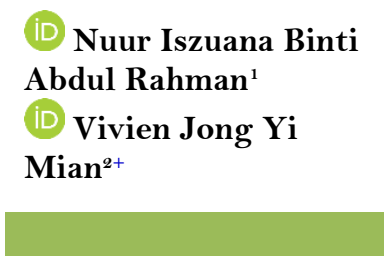

${ }^{1,2}$ Faculty of Applied Sciences, Universiti Teknologi MARA Sarawak, Kota Samarahan, Sarawak, Malaysia. 'Email:nuuriszuana_ara@yahoo.com Tel: +60128496009 ${ }^{2}$ Email: vivien@uitm.edu.my Tel: +60165758037

\section{Article History}

Received: 2 August 2021 Revised: 6 September 2021 Accepted: 29 September 2021 Published: 20 October 2021

\section{Keywords}

Morinda citrifolia Metabolomics NMR GCMS- based Principal component analysis Soil.
ABSTRACT

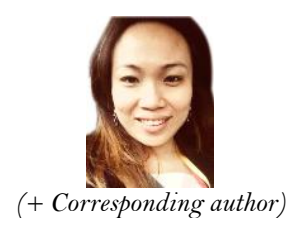

Morinda citrifolia or Noni is known as an important dietary supplement, food functional ingredient, or as natural health enhancer that is used throughout the world. Different parts of the plant have been proven to carry compounds that have high medicinal values such as terpenoids, alkaloids and anthraquinones. The stem bark of Morinda citrifolia collected from different types of soil were studied. It aimed to investigate the influence of different geographical factor on its metabolite profile by multivariate statistical analyses of spectral data deduced by NMR methods. A metabolomic approach employing concatenated GCMS and NMR data was utilized to study the relationships between environment and plant metabolism. Morinda citrifolia stem barks were pulverized into fine powder. They were extracted using chloroform and were taken to dryness in a rotary evaporator under reduced pressure. The Morinda citrifolia crudes were proceeded for Nuclear Magnetic Resonance (NMR) analysis. Visual inspection on the ${ }^{1} \mathrm{H}-\mathrm{NMR}$ Morinda citrifolia spectra showed that the different geographical areas have similar profile, but they have different concentration of various constituents. Major constituents identified were aromatics $\left(\delta_{\mathrm{H}} 7.25-7.50\right)$, sugars and glycosides $\left(\delta_{\mathrm{H}}\right.$ 2.25-5.0), fatty acids/aliphatics ( $\delta_{\mathrm{H}}$ 0.5-2.0) and aldehydic compound ( $\delta_{\mathrm{H}}$ 9.75). However, since the difference among the geographical areas were not clear from visual analysis, the analysis was proceeded using multivariate analysis, Principal Component Analysis (PCA) model. Thus, further analysis was done to examine the consistency of geographical area for each batch of Morinda citrifolia. This is to identify which type of soil is suitable as class model.

Contribution/ Originality: A metabolomic approach employing concatenated GCMS and NMR data was utilized for the first time to study the relationships between environment and plant metabolism.

\section{INTRODUCTION}

Morinda citrifolia is the scientific name for the Noni tree. The Morinda citrifolia plant is commercially known as 'noni', where Noni is the Hawaiian name for the fruit of Morinda citrifolia. It is also called 'Indian mulberry', 'nuna' or 'arch' in Indian subcontinent; 'mengkudu' in Malaysia; 'nhau' in Southeast Asia; 'painkiller bush' in the Caribbean or 'cheese fruit' in Australia [1-5]. Noni is originally native from Southeast Asia and was spread to Australia, Hawaii, French Polynesia Islands and other tropical areas through possible water-dispersal of buoyant seeds or by being transported by early migrants or voyagers.

Noni plant has been around for nearly 2000 to 3000 years. Traditionally, noni plant has been used as food, dye as well as medicinal purposes to cure several diseases [6]. Different parts of the plants which include the fruits, 
leaves, bark and roots have been proven to carry active compounds that have high medicinal values [7]. Some of the active components identified in the plant were terpenoids, alkaloids and anthraquinones. The fruits and leaves of Noni plants are fit for human consumption and have been used as a food and in herbal remedies to maintain overall health and to heal various diseases such as diabetes, treating swollen spleen, liver diseases and cough. The fruits are also used to stimulate the immune system and thus to fight bacterial, viral, parasitic and fungal infections, as well as used to prevent the formation and proliferation of tumors $[8,9]$. Whereas the roots of Noni plants were used by the Polynesians to produce yellow or red dye. In addition, the roots contain medicinally active components such as anthraquinones which have been found to possess several therapeutic effects. These components exhibited antibacterial, anti-viral and anti-cancer activities as well as analgesic effects which make the roots potentially practical in several medical applications [10]. Noni is commonly used in the diet of many cultures and as famine food in some countries where Noni juice is the usual form of consumption. Therefore, most Noni is consumed as juice even though the leaves, flowers, bark, and roots can also be used. In fact, the pulp of this fruit has incredible healing and pain-relieving properties, whether to be eaten or applied to the skin.

Noni plant contained about 160 biologically active compounds or phytochemical compounds that have been identified, where the major micronutrients are phenolic compounds, organic acids and alkaloids [11]. The most important phenolic compounds found in Noni are anthraquinones (morindone, morindin, etc.), and aucubin, asperuloside, and scopoletin. The main organic acids are caproic and caprylic acids, whereas the main found alkaloid is xeronine. Noni fruit also contains proxeronine, which is converted to xeronine in the body by enzyme proxeroninase. Apart from that, there are also several metabolites that have been described including polysaccharides, fatty acid, glycosides, iridoids, triterpenoid, coumarins, flavonoids, lignans, phytosterols, carotenoids and a range of volatile constituents including monoterpenes, short chain fatty acids and fatty acid esters [12]. However, chemical composition differs greatly according to the part of the plant. Different parts of Noni plant have been the proposed subject of medicinal research to investigate its effects on health.

The commercialization potential of Noni fruits as a medicinal food and dietary supplement has tremendously facilitated its availability worldwide, encouraged its use as well as brought its benefits to more people. Countless of Noni products have emerged in the global market such as dried Noni fruit, Noni fruit juice, Noni tea, and Noni capsules. Nevertheless, the quality of commercial Noni fruit products may differ significantly, attributing to different geographical conditions such as soil, sunlight, precipitation, and air and post-growth factors which include harvesting, storage, transportation, and manufacturing processes. Thus, there are concerns on the consistency of phytochemical profiles of Noni fruits from different locations. To address these concerns, analytical NMR- and GCMS- based metabolomics approach can be developed to conduct an extensive quantitative comparison of characteristics components in Noni stem barks from different geographical areas which are three different types of soil, namely sandy, silty and clay soil. As such, this study aimed to study the relationships between environment and plant metabolism because different environmental changes influence the phytochemicals in Morinda citrifolia.

\section{MATERIALS AND METHODS}

\subsection{Sample Preparation}

At least $500 \mathrm{~g}$ of stem bark of Morinda citrifolia (Noni) was collected from three different types of soil; sandy, silty and clay soil. The stem bark was cut into tiny little pieces and then dried in an oven for four days at $39^{\circ} \mathrm{C}$. The dried stem barks were grinded into powder form by using a laboratory grade grinding machine and mortar and pestle. The powdered sample of Morinda citrifolia was carefully transferred into conical flasks and soaked with chloroform for 48 hours at room temperature. The conical flasks were covered with aluminium foil to prevent the evaporation of the solvent. After two days, the mixtures were then filtered, and the solvent was removed under reduced pressure using a rotary evaporator Buchi Rotavapor R-215. These extracted samples were subjected to sample extraction for NMR and GCMS analysis respectively. 


\subsection{General Instrumentation}

\subsubsection{Nuclear Magnetic Resonance (NMR) Spectrometer}

$\mathrm{CDCl}_{3}$ deuterated solvent was used to obtain proton NMR 1D spectra (zg30, zgpr, NOESY and CPMG) and 2D spectra (JRES and HSQC) by using Bruker $400 \mathrm{MHz}$ NMR spectrometer with tetramethylsilane (TMS) as the internal standard. ${ }^{1} \mathrm{H}$ NMR enable to identify the chemical constituents of the samples.

\subsection{Chromatography Mass Spectrometer (GCMS)}

The purity of the compound and its molecular weight was obtained from Perkin Elmer Clarus 680 Mass Spectrometer. The gas chromatography was used to detect the secondary metabolites of the samples. The samples were injected with helium as the carrier gas. The initial temperature was set at $50^{\circ} \mathrm{C}$ and hold for two minutes. The temperature was then ramped to $280^{\circ} \mathrm{C}$ at a rate of $6.5^{\circ} \mathrm{C} / \mathrm{min}$, and it was hold for 10 minutes. The temperature for injector and detector of the gas chromatography were set at $250^{\circ} \mathrm{C}$. The compound was identified by comparing it with the mass spectrum data.

\subsection{NMR Measurements}

2.4.1. NMR Sample Preparation

Samples for NMR measurements were prepared by resuspending $20 \mathrm{mg}$ of each sample extract in $700 \mu \mathrm{L}$ chloroform-d $\left(\mathrm{CDCl}_{3}\right)$ to which $5 \%$ tetramethylsilane (TMS) was added as reference standard. The sample-solvent mixtures were transferred to $5 \mathrm{~mm}$ NMR tubes for NMR data acquisition.

\subsection{Data Acquisition}

${ }^{1} \mathrm{H}$ NMR spectra were recorded at $25^{\circ} \mathrm{C}$ on a $400 \mathrm{MHz}$ NMR (Bruker) spectrometer, using 128 scans over a proton frequency range of $15 \mathrm{ppm}$. The water suppression program was used to suppress undesirable signals caused by residual water.

\subsection{Data Processing}

The generated ${ }^{1} \mathrm{H}$ NMR FIDs were manually processed, phased, and referenced to the internal standard, TMS ( $\delta 0.00 \mathrm{ppm})$. Water and solvent peaks which displayed in the regions of $\delta 4.70$ to $\delta 4.96$ and $\delta 3.28$ to $\delta 3.33 \mathrm{ppm}$, respectively were excluded from the multivariate analysis.

\subsection{Multivariate Data Analysis}

Principle Component Analysis (PCA) was carried out using AMIX Bruker program software. Bruker's AMIX program enabled unsurpassed integration of spectroscopy and metabolomics where it offered a range of powerful tools that provide several integrated routines for spectroscopic and statistical analyses. AMIX then completely integrated the statistical and spectroscopic analysis of NMR by using PCA to better find valid metabolomic results. PCA is a technique that automatically extract and display any natural variation in a data matrix.

\section{RESULT AND DISCUSSION}

\subsection{NMR-Based Discriminative Analysis of Different Types of Soil of Morinda Citrifolia (Noni) \\ 3.1.1. Visual Analysis of ${ }^{\prime} H$ NMR Spectra}

The representative of ${ }^{1} \mathrm{H}$ NMR spectrum of the chloroform extract for each type of Morinda citrifolia (Noni), named Sample A (silty soil), Sample B (sandy soil) and Sample C (clay soil) is shown in Figure 1. A visual inspection of the spectra indicated that each type has very similar profile with the expected differences in concentration of the various constituents. The major chemical constituents of the extract consisted of aromatics $\left(\delta_{\mathrm{H}} 7.25-7.50\right)$, sugars and glycosides $\left(\delta_{\mathrm{H}} 2.25-5.0\right)$, and fatty acids/aliphatics $\left(\delta_{\mathrm{H}} 0.5-2.0\right)$. 


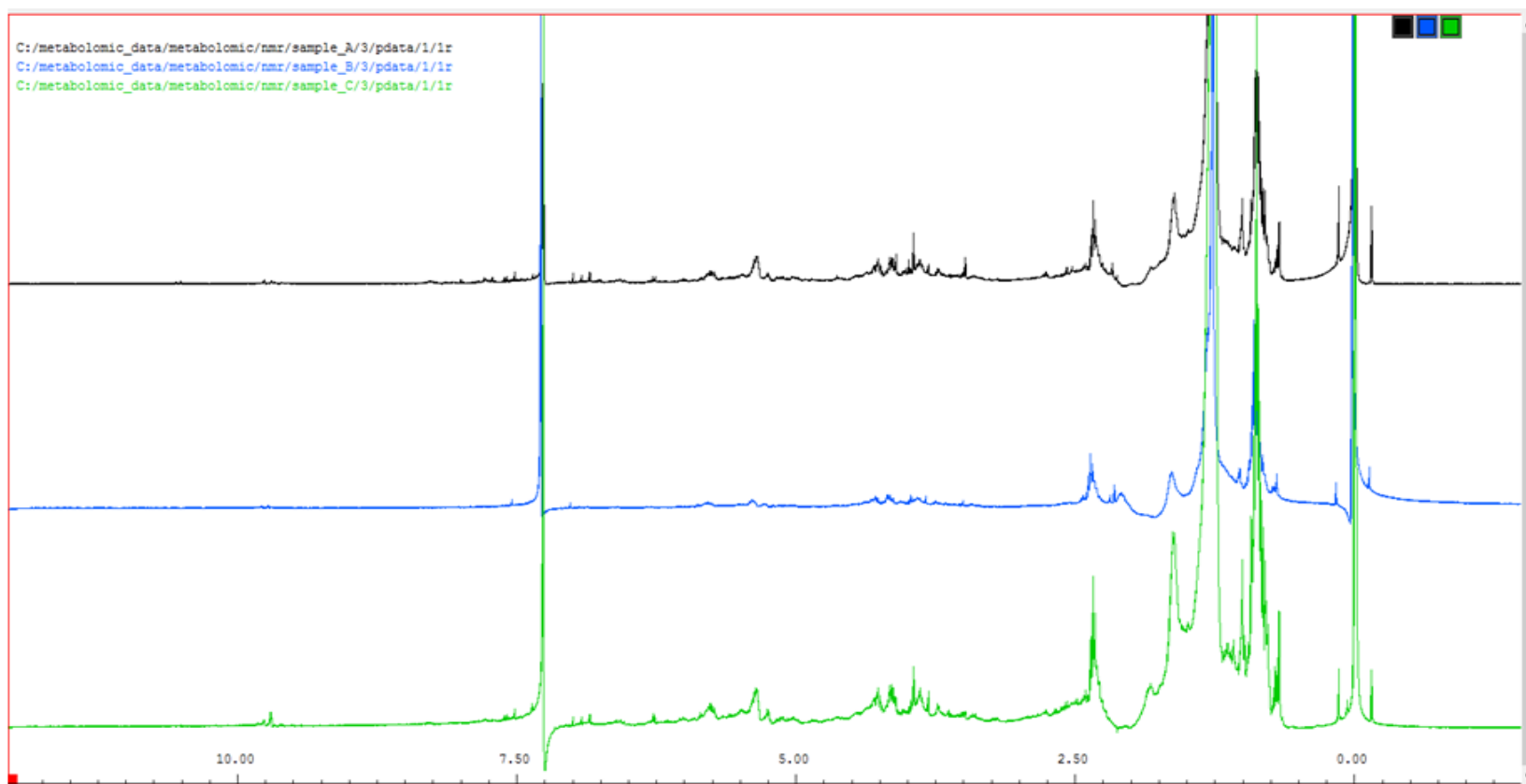

Figure-1. ${ }^{1} \mathrm{H}$ NMR spectra of the Morinda citrifolia (Noni) extracts from $\delta_{\mathrm{H}}$ 0.5-10.0 ppm. Black indicates Sample A; Blue indicates Sample B; and Green indicates sample C.

Closer examination of the spectra showed that the Noni extracts also contain small proportion of aldehydic compounds as can be seen in Figure 2 which shows the expanded aldehydic region. The aldehyde peaks $\left(\delta_{\mathrm{H}} 9.7 \mathrm{ppm}\right)$ were markedly higher in Noni sample C. Other differences between the spectra were not very distinct by visual inspection. Thus, it required the multivariate analysis to discriminate between the different soil types.

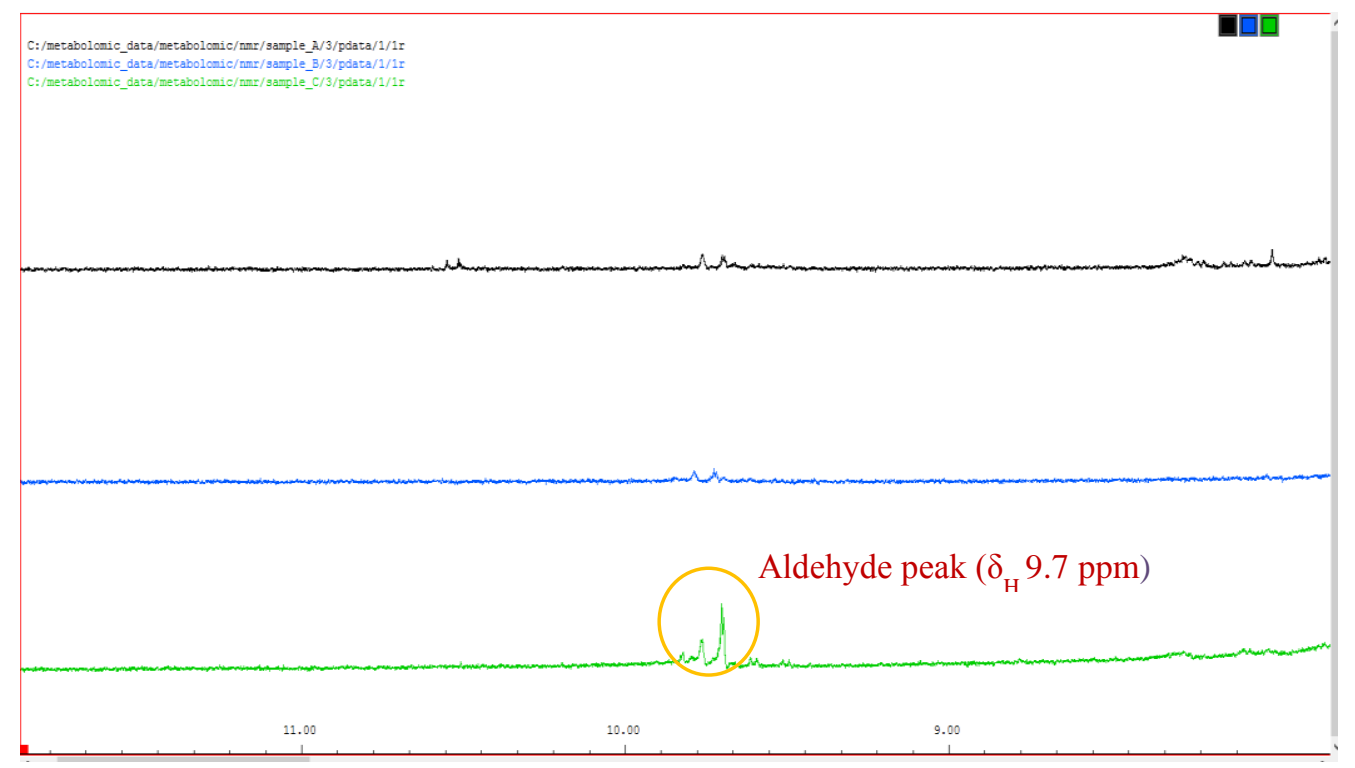

Figure-2. Expanded aldehydic region.

\subsection{Multivariate Analysis of ${ }^{\prime} H$ NMR Spectra of Various Soil Types of Noni}

Since the differences among the soil types were not clear from the visual analysis, multivariate analysis needs to be applied to the NMR data to prevent bias or misinterpretation. The unsupervised method of Principal Component Analysis (PCA) was applied to build a model since PCA is a technique which can automatically extract and display any natural variation in a data matrix without any external intervention or supervision [13]. 
A spectrum with $\mathrm{n}$ peaks can be plotted in a n-dimensional space, and these two are equivalent. The PCA transforms the original coordinate system in which the new coordinates are called principal components. The values that the spectra have in the PC-coordinate system are called scores. As seen in Figure 3, PCA was not able to properly discriminate between the types of soil. The left side of the PCA plot represents the scores plot and each spectrum is assigned to different colors, where each spectrum indicates the different type of soil. The PCA plot below consists of three different types of soil spectrum of different batches which are represented by the color code black for silty soil; color code blue for sandy soil; and color code green for clay soil. From the PC-coordinate system, there seem to be scattered and the PCA does not tell which spectra belong together. Although the different colors for different classes (types of soil) were seen in the scores plot, but PCA is not a classification, instead it can be used as the basis of a classification, where the different colors that come from each spectrum represents its class.

From the loadings plot Figure 3, the PCA is a transformation of the old coordinate system (peaks) into the new coordinate system (PC). It estimated how much each of the old coordinates (peaks) contribute to each of the new ones (PCs), where these values are called loadings. The higher the loading of a peak onto a PC, the more it contributes to that PC. Each point (dot) in the corresponding loadings plot below represents a peak and every dot also represents a bucket. Thus, loadings plot indicating buckets at various chemical shifts. From the PCA plot for all types of soil of Noni shown below, these three types of soil gave almost the same chemical constituents as most of the buckets clustered in the middle.

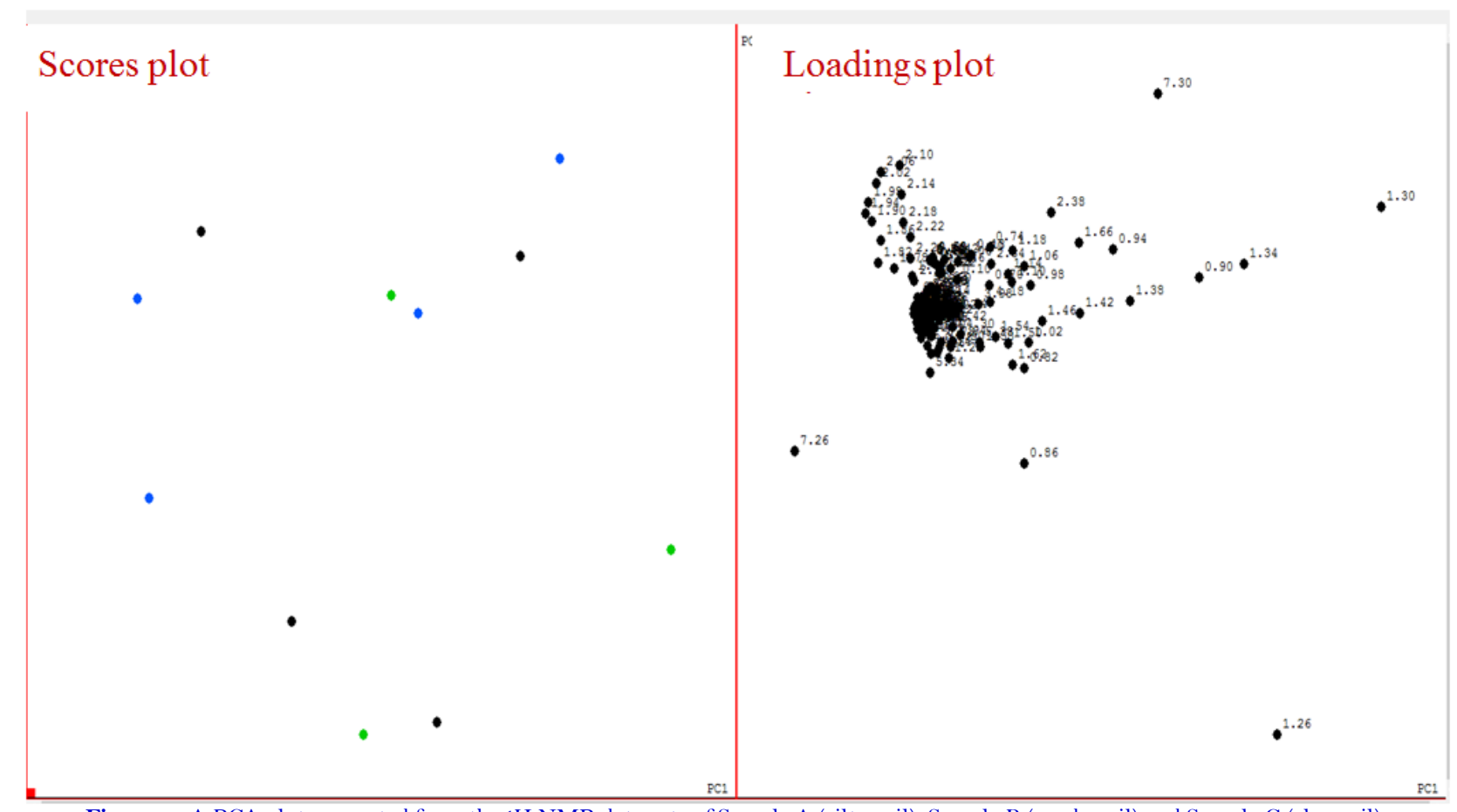

Figure-3. A PCA plot generated from the ${ }^{1} \mathrm{H}$ NMR data sets of Sample A (silty soil), Sample B (sandy soil) and Sample C (clay soil).

The initial PCA plot was not able to provide any useful information about the different types of Noni samples, but the Noni samples were differentiated according to subjective criteria, where it was decided to analyse the consistency of the individual soil types for Noni samples. Thus, class models were constructed by creating PCA plot data matrix according to different types of Noni's soil. This PCA plot by type is meant to see which types are more consistent in order to create a class model. 


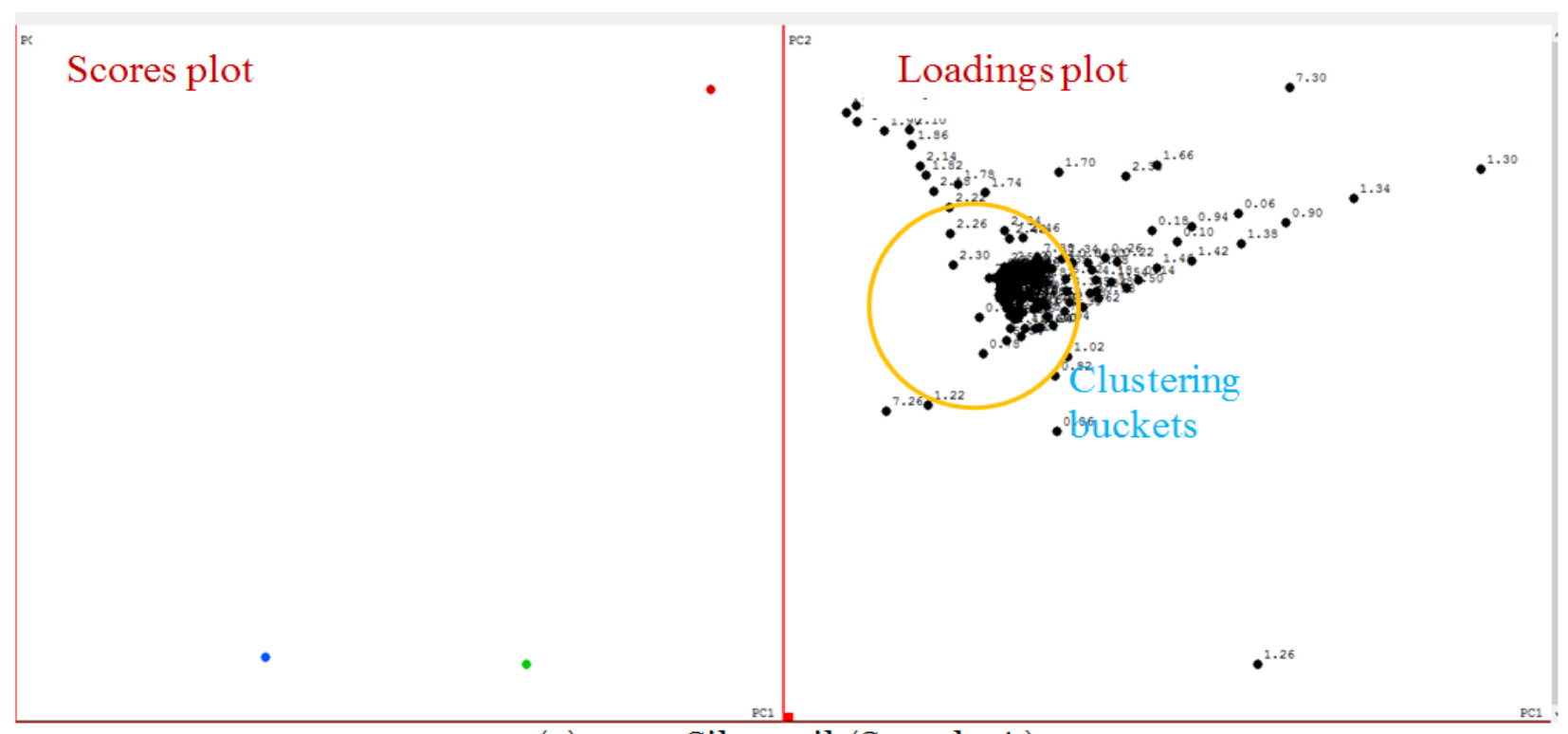

(a)

Silty soil (Sample A)

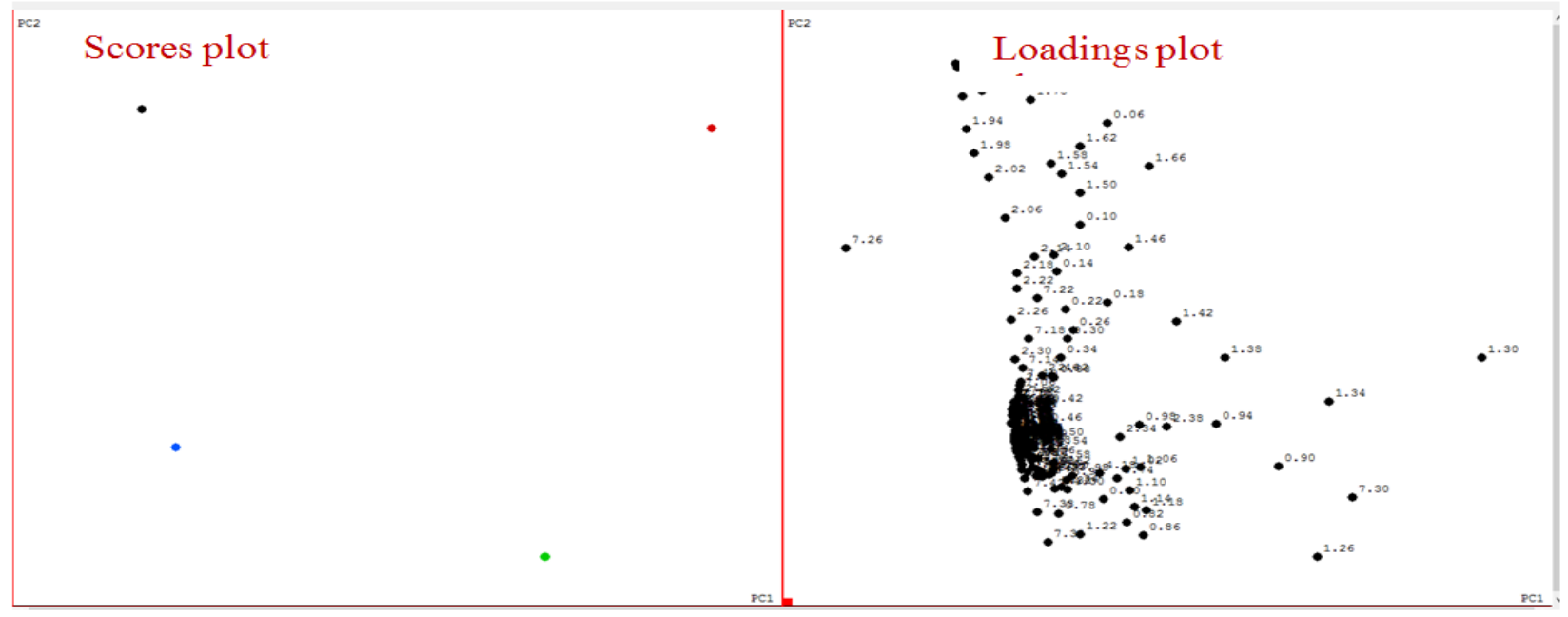

(b)

Sandy soil (Sample B)

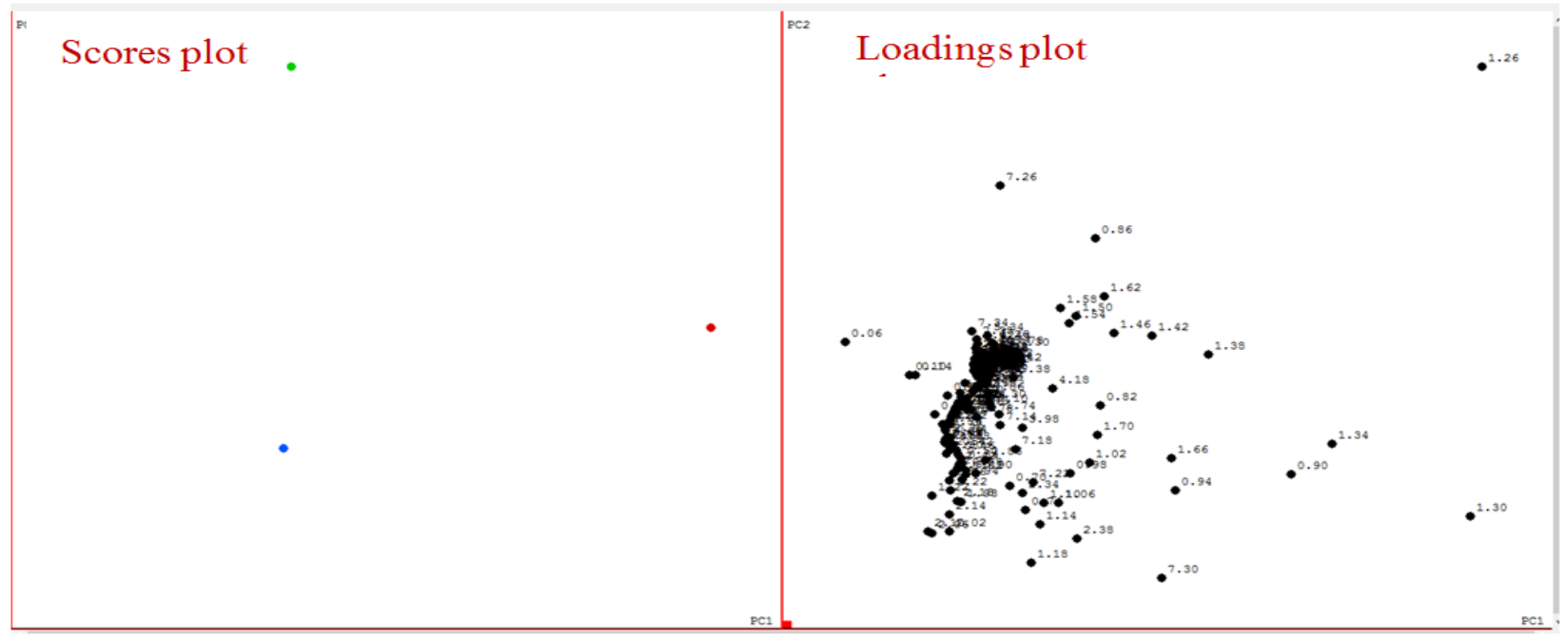

(c) Clay soil (Sample C)

Figure-4. PCA plot by soil types (a) silty soil, (b) sandy soil, and (c) clay soil.

The PCA loadings plots for each type of Noni's soil are illustrated in Figure 4(a-c). Each dot illustrates a bucket at certain chemical shift. From the loadings plots above, it can be seen that batch to batch variation for the types were greater for sandy soil (Sample B) in comparison to silty soil (Sample A) and clay soil (Sample C). Silty 
soil (Sample A) has the most consistent buckets, which means that it is a good class model and this model is predictable. This silty soil (Sample A) gave nearly the same chemical constituents as its buckets is clustering. In addition, it is most consistent at the center due to less scattering of the buckets, while for sandy soil (Sample B) and clay soil (Sample C), the buckets are more scattered, which means that it is not imperative to have the same chemical constituents.

These loadings plots indicated each plot for different types of soil have different clustering or scattering dots, which means they have different buckets, as well as different chemical shifts. However, the strong inconsistency of buckets in Sample B (sandy soil) and Sample C (clay soil) may be due to the environmental factors such as the location or surrounding of the Noni plant that is not convinced. Geographical location is the primary factor for inconsistency of the buckets which are due to the difference in chemical constituents or secondary metabolites.

\subsection{GCMS-Based Discriminative Analysis Of Crude Extract From Different Types of Soil of Morinda Citrifolia (Noni) 3.3.1. Visual Analysis of GCMS Chromatogram}

Noni extracts are expected to contain aldehyde and aromatics. From the chromatograms, it is noted that all different types of soil having almost identical retention time which indicated they are having similar secondary metabolites. Furthermore, the chemical profiles of the different types of soil in the NMR spectral data are mostly similar. In this study, the chemical constituents identified based on the NIST in the extracts include pentanal (aldehyde), xylitol (sugar) and daidzin (aromatic). The list of chemical constituents present in all three types of Noni soil are summarized in Table 1.

Table-1. Chemical constituents identified in Noni extracts of Sample A (silty soil), Sample B (sandy soil) and Sample C (clay soil).

\begin{tabular}{c|c|c}
\hline No. & Compound Name & Retention Time \\
\hline $\mathbf{1 .}$ & Erythritol & 2.19 \\
\hline $\mathbf{2 .}$ & Xylitol & 2.19 \\
\hline $\mathbf{3 .}$ & Pentanal & 1.55 \\
\hline $\mathbf{4 .}$ & Acetohydroxamic acid & 1.55 \\
\hline $\mathbf{5 .}$ & Cycloserine & 1.56 \\
\hline $\mathbf{6 .}$ & Daidzin & 1.56 \\
\hline
\end{tabular}

Funding: This study received no specific financial support.

Competing Interests: The authors declare that they have no competing interests.

Acknowledgement: Both authors highly acknowledges to several individuals and organizations especially Associate Prof. Dr. Vivien Jong Yi Mian and Universiti Teknologi MARA Sarawak for guidance and relentless support in improving my research.

\section{REFERENCES}

[1] D. Cardon, The world of natural dyes. Paris: Belin, 2003.

[2] J. F. Morton, "The ocean-going noni, or Indian Mulberry (Morinda citrifolia, Rubiaceae) and some of its "colorful" relatives," Economic Botany, vol. 46, pp. 241-256, 1992. Available at: https://doi.org/10.1007/bfo2866623.

[3] S. C. Nelson, "Noni cultivation in Hawaii," Fruit and Nuts, vol. 4, pp. 1-4, 2001.

[4] I. A. Ross, Medical plants of the world: Chemical constituents, traditional and modern medical uses. New Jersey: Humana Press, 2001.

[5] M.-Y. WANG and C. Su, "Cancer preventive effect of Morinda citrifolia (Noni)," Annals of the New York Academy of Sciences, vol. 952, pp. 161-168, 2001.

[6] M.-Y. Wang, B. J. West, C. J. Jensen, D. Nowicki, C. Su, A. K. Palu, and G. Anderson, "Morinda citrifolia (Noni): A literature review and recent advances in Noni research," Acta Pharmacologica Sinica, vol. 23, pp. 1127-1141, 2002. Available at: https://doi.org/10.1002/ptr.2842. 
[7] S. Hemwimol, P. Pavasant, and A. Shotipruk, "Ultrasound-assisted extraction of anthraquinones from roots of Morinda citrifolia," Ultrasonics Sonochemistry, vol. 13, pp. 543-548, 2006. Available at: https://doi.org/10.1016/j.ultsonch.2005.09.009.

[8] A. R. Dixon, H. McMillen, and N. L. Etkin, "Ferment this: the transformation of Noni, a traditional Polynesian medicine (Morinda citrifolia, Rubiaceae)," Economic Botany, vol. 53, pp. 51-68, 1999. Available at: https://doi.org/10.1007/bfo2860792.

[9] J. E. Earle, Medicinal plants in the humid tropics. San José: Editorial Guayacán, 2001.

[10] K. Kiathevest, M. Goto, M. Sasaki, P. Pavasant, and A. Shotipruk, "Extraction and concentration of anthraquinones from roots of Morinda citrifolia by non-ionic surfactant solution," Separation and Purification Technology, vol. 66, pp. 111-117, 2009. Available at: https://doi.org/10.1016/j.seppur.2008.11.017.

[11] J. Wang, X. Qin, Z. Chen, Z. Ju, W. He, Y. Tan, X. Zhou, Z. Tu, F. Lu, and Y. Liu, "Two new anthraquinones with antiviral activities from the barks of Morinda citrifolia (Noni)," Phytochemistry Letters, vol. 15, pp. 13-15, 2016. Available at: https://doi.org/10.1016/j.phytol.2015.11.006.

[12] A. N. Ahmad, Z. A. Mat Daud, and A. Ismail, "Review on potential therapeutic effect of Morinda citrifolia L," Current Opinion in Food Science, vol. 8, pp. 62-67, 2016. Available at: https://doi.org/10.1016/j.cofs.2016.03.002.

[13] L. Eriksson, E. Johansson, N. Kettaneh-Wold, J. Trygg, C. Wikstrom, and S. Wold, Multi-and megavariate data analysis basic principles and applications. Sweden: Umetrics Academy, 2006.

Views and opinions expressed in this article are the views and opinions of the author(s), Journal of Asian Scientific Research shall not be responsible or answerable for any loss, damage or liability etc. caused in relation to/arising out of the use of the content. 